\title{
PREVALÊNCIA DE OBESIDADE E SÍNDROME METABÓLICA EM FREQUENTADORES DE UM PARQUE
}

\author{
Obesity prevalence and metabolic syndrome in a park users
}

Maíra Danielle Gomes de SOUZA ${ }^{1}$, Lucio VILAR ${ }^{1}$, Cinthia Barbosa de ANDRADE ${ }^{1}$, Raíssa de Oliveira e ALBUQUERQUE ${ }^{2}$, Lúcia Helena de Oliveira CORDEIRO ${ }^{1}$, Josemberg Marins CAMPOS $^{1,2}$, Álvaro Antônio Bandeira FERRAZ ${ }^{1,2}$

From the ${ }^{1}$ Programa de Pós-Graduação em Cirurgia and ${ }^{2}$ Departamento de Cirurgia e Medicina Clínica, Universidade Federal de Pernambuco ('Postgraduate Program in Surgery and ${ }^{2}$ Department of Surgery and Clinical Medicine of the Federal University of Pernambuco), Recife, PE, Brazil.

HEADINGS - Obesity. Overweight. Diabetes mellitus. Metabolic syndrome.
ABSTRACT - Background - Overweight and obesity are associated with metabolic syndrome and abdominal obesity, thereby increasing the risk of type 2 diabetes mellitus and cardiovascular diseases. In Brazil, there are still no precise data on the prevalence of these disorders, especially among individuals who carry out some kind of physical activity in public spaces and there are no education and prevention programs for obesity. Aim: To investigate the prevalence of metabolic syndrome and obesity among park users. Methods: A prospective, cross-sectional, descriptive study was conducted with 619 individuals assessed and stratified by profile according to a specific protocol. The group was characterized as follows: female (50.1\%) and mean age $=50.6 \pm 14.8$, with predominance of individuals aged between 50 and 59 years (26.8\%) and with higher education (68\%) and a household income of between 4 and 10 minimum wages (29.2\%). Results: Regular physical exercise was reported by $78 \%$ of the individuals and it was found that $70.7 \%$ were nevertheless of above normal weight: $45 \%$ overweight and $25.7 \%$ obese, of whom $20.7 \%$ had obesity grade I, 3.9\% grade II and $1.1 \%$ grade III. The prevalence of metabolic syndrome was $4.3 \%$, mostly in men (6.3\%). Arterial hypertension and type 2 diabetes mellitus were detected in $17.8 \%$ and $5.5 \%$, respectively. In view of the influence of obesity on the occurrence of type 2 diabetes mellitus and metabolic syndrome, it was found that this association was not significant for the two conditions ( $p=0.014$ and 0.017 , respectively). Conclusion: The findings demonstrate a high prevalence of overweight and obesity in the studied population, and metabolic syndrome in $4.3 \%$, despite the fact that $70 \%$ reported engaging in regular physical activity.

\section{Correspondence:}

Maíra Danielle Gomes de Souza

E-mail: maira.dgomes@gmail.com

Financial source: none

Conflicts of interest: none

Received for publication: 14/04/2015 Accepted for publication: $16 / 07 / 2015$

DESCRTORES: Obesidade. Sobrepeso. Diabete melito. Síndrome metabólica.
RESUMO - Racional: Sobrepeso e obesidade estão associados à síndrome metabólica e obesidade abdominal, aumentando o risco de diabete melito tipo 2 e doenças cardiovasculares. No Brasil, ainda não há dados precisos sobre a prevalência destas alterações, principalmente entre pessoas que estão realizando algum tipo de atividade física em ambientes públicos; também não há programas de educação e prevenção da obesidade. Objetivo: Investigar a prevalência da obesidade e síndrome metabólica em frequentadores de um parque em Recife. Métodos: Realizou-se um estudo prospectivo, transversal e descritivo, onde 619 indivíduos foram avaliados e estratificados por perfil definido em protocolo específico, apresentando as seguintes características: sexo feminino $(50,1 \%)$ e média de idade $=50,6 \pm 14,8$, havendo predomínio entre 50 e 59 anos (26,8\% dos casos) e de indivíduos com ensino superior (68\%) e renda familiar entre 4 e 10 salários mínimos (29,2\%). Resultados: Prática regular de exercícios físicos foi relatada por $78 \%$ das pessoas e foi constatado ainda que $70,7 \%$ apresentavam excesso de peso: $45 \%$ com sobrepeso e $25,7 \%$ obesidade, dos quais $20,7 \%$ com obesidade grau I, 3,9\% com grau II e 1,1\% com grau III. A prevalência de síndrome metabólica foi de $4,3 \%$, com predomínio nos homens (6,3\%). Hipertensão arterial e diabetes mellitus tipo 2 foram detectados em $17,8 \%$ e 5,5\%, respectivamente. Devido a influência da obesidade na ocorrência de diabetes mellitus 2 e síndrome metabólica, foi constatado que esta associação não é significativa para as duas condições ( $p=0,014$ e 0,017 , respectivamente). Conclusão: Os achados demonstram elevada prevalência de sobrepeso e obesidade da população avaliada, e síndrome metabólica em $4,3 \%$, apesar do relato de que $70 \%$ dos transeuntes realizavam atividade física regular.

\section{INTRODUCTION}

$\mathrm{O}$ verweight and obesity affect around two billion people around the world and are considered to be pandemic ${ }^{17,18}$. Brazil ranks fifth in the world, with around 60 million overweight and 22 million obese individuals, representing $17 \%$ of the population ${ }^{16}$. This leads to increased mortality as a result of the risk of developing other diseases, such as type 2 diabetes mellitus (DM2), systemic arterial hypertension (SAH), dyslipidemia, sleep apnea, cardiovascular diseases and certain kinds of cancer ${ }^{9,13}$. The increasing prevalence of DM2 $2^{16,26}$ indicates the need for early detection and adequate control of these disorders.

Metabolic syndrome (MS) is a complex of interrelated risk factors for cardiovascular 
disease and DM2, including hyperglycemia, $\mathrm{SAH}$, dyslipidemia and abdominal obesity ${ }^{1}$. It is estimated that MS affects $20 \%$ to $25 \%$ of the adult population and prevalence is on the increase, owing to obesity and a sedentary lifestyle ${ }^{1,11}$, affecting as many as $42 \%$ of individuals aged over 60 years ${ }^{1,11}$. Taken separately, the components of MS increase the risk of DM2, cardiovascular disease and mortality from all causes, although full-blown MS carries a risk higher than that of all the individual components combined ${ }^{8}$. It has been reported that the association between MS and cardiovascular disease increases total mortality by a factor of 1.5 and cardiovascular mortality by a factor of $2.5^{21}$. People with MS have five times greater risk of developing DM2 ${ }^{11}$. In fact, MS is found in $42-64 \%$ of individuals with pre-diabetes and $78-84 \%$ of those with $D M 2^{12}$. In these individuals cardiovascular morbimortality is significantly higher when MS is present ${ }^{12}$.

Despite the importance of MS in the context of metabolic and cardiovascular diseases, few studies in Brazil have assessed its prevalence and determining factors, limiting the quality of information available on the scale of the problem in the country. A recent systematic review of ten studies, none of them involving adults from the Northeast region, found prevalence of MS of around $29 \%{ }^{23}$.

Weight loss is essential for obese individuals, whether or not they have MS. Physical exercise and dieting are thus very important for treatment. Health services should encourage healthy habits, and, in view of the low public investment training in health education, there is a need to develop strategies to improve performance and tract obesity and its comorbidities, in which a trained multidisciplinary team plays a fundamental role, thereby minimizing costs to the public health system.

The main aim of the present study was to assess the prevalence of obesity and associated diseases, such as $\mathrm{DM} 2, \mathrm{SAH}$ and $\mathrm{MS}$ in a population of park users in the city of Recife, PE, Brazil.

\section{METHODS}

The present study was approved by the Ethics Committee of the Federal University of Pernambuco's Center for Health Sciences (CEP/CCS/UFPE) ( $n^{\circ}$ 915.390/2014) CAAE: 38937514.2.0000.5208. It adopted a prospective, crosssectional, descriptive and quantitative approach and was a population-based epidemiological study conducted in the Jaqueira Park, a leisure area in Recife, frequented daily by around 3000 individuals. The sample comprised 619 individuals, who were assessed and stratified according to profile. Assuming a confidence level of $95 \%$, a sample error of $5 \%$ and the number of visitors to the park per day, a sample size of 341 is considered representative.

Six interventions were carried out focusing primarily on providing guidance to the population with regard to risk factors for obesity, SAH, DM2 and MS. "Tests" were carried out (measurement of arterial pressure, weight and height; body mass index [BMI], abdominal perimeter and capillary glycemia) and a standardized questionnaire was applied covering age, sex, level of education, household income, frequency of physical exercise. The interviews were conducted by an appropriately trained multidisciplinary team. The park users who presented with some alteration in these parameters were advised to attend the family health unit closest to their place of residence or consult a specialist.

Individuals of both genders aged 18 years or over were included in the study. Exclusion criteria included pregnancy and some kinds of mental illness that might impede understanding of the procedures carried out.

\section{Dependent variables}

Metabolic syndrome

The criteria followed were those established by the International Diabetes Federation, including abdominal obesity in South Americans (abdominal circumference $\geq 90$ $\mathrm{cm}$ in men and $\geq 80 \mathrm{~cm}$ in women), combined with two or more parameters: $\mathrm{SAH}$ (systolic arterial pressure $\geq 30 \mathrm{mmHg}$ or diastolic $\geq 85 \mathrm{mmHg}$ ); dyslipidemia and hyperglycemia (glycemia $\geq 100 \mathrm{mg} / \mathrm{dl}$ on fasting or glycemia $\geq 200 \mathrm{mg} / \mathrm{dl}$ after eating $)^{11}$.

\section{Obesity}

The body mass index (BMI) was used as a diagnostic parameter, in accordance with the criteria of the World Health Organization $(\mathrm{WHO})^{27}$.

\section{Diabetes mellitus}

The diagnostic criterion followed the recommendations of the American Diabetes Association, namely, fasting glycemia $\geq 126 \mathrm{mg} / \mathrm{dl}$ or random glycemia $\geq 200 \mathrm{mg} / \mathrm{dl}$, in combination with classic symptoms of the disease ${ }^{2}$. Hyperglycemia was defined as fasting glycemia $\geq 100 \mathrm{mg} / \mathrm{dl}$ or random glycemia $\geq 200 \mathrm{mg} / \mathrm{dl}^{2}$.

\section{Systemic arterial hypertension (SAH)}

Diagnosis was based on the recommendations contained in the $6^{\text {th }}$ edition of the Brazilian Guidelines on Hypertension, in which SAH is classified into three stages according to systolic arterial pressure (SAP) and diastolic arterial pressure (DAP), respectively: stage 1 (140-159/90-99 $\mathrm{mmHg})$; stage 2 (160-179/100-109 $\mathrm{mmHg}) ;$ and stage $3(\geq 180 / \geq 110 \mathrm{mmHg})^{22}$.

\section{Independent variables}

Sociodemographic

Gender, age, level of education (classified according to number of years of formal schooling) and household income ( $R \$$ - Brazilian reais).

\section{Behavioral \\ Frequency of physical exercise.}

\section{Statistical analysis}

The sample size was calculated using the Epi Info program Version 3.01, with a confidence level of $95 \%$. A data bank was built up using Microsoft Excel and exported to SPSS for analysis. The profile of the participants was established by calculating percentage frequencies and drawing up respective frequency distributions for the factors under investigation (physical activity, distribution of BMI, MS, SAH and DM2). The chi-squared test was applied to compare the proportion and prevalence of comorbidities per study factor and also for independence, as a way of confirming the relation between obesity and DM2 and MS. In cases in which the association was significant, the odds ratios were calculated and used to measure the likelihood of obese individuals developing DM2 and MS compared to nonobese participants. All conclusions were obtained using a level of significance of $5 \%$ and confidence interval of $95 \%(p=0.05)$.

\section{RESULTS}

\section{Characteristics of the participants}

The profile distribution of the 619 participants showed that $50.1 \%$ were female and age varied from 18 to 88 years (mean $50.6 \pm 14.8$ ), most falling in the $50-59$ year age bracket (26.8\% of cases).

\section{Weight Status}

It was found that $45 \%(n=276)$ of participants were overweight $\left(\mathrm{BMI}^{3} 25\right.$ and $\left.<30 \mathrm{~kg} / \mathrm{m}^{2}\right)$ and $25.7 \%(\mathrm{n}=158)$ obese, 
of whom $20.7 \%(n=127)$ were classified as grade 1 (BMI between 30 and $\left.34.9 \mathrm{~kg} / \mathrm{m}^{2}\right) ; 3.9 \%(\mathrm{n}=24)$ as grade II (BMI between 35 and $\left.39.9 \mathrm{~kg} / \mathrm{m}^{2}\right)$ and $1.1 \%(\mathrm{n}=7)$ as grade III $\left(\mathrm{IMC}^{3} 40 \mathrm{~kg} / \mathrm{m}^{2}\right)$ (Table 1). The prevalence of obesity did not differ between men and women (27.1\% vs. $24.4 \% ; p=0.432$ ) (Table 2 ).

TABLE 1 - Distribution of BMI, arterial pressure and glycemia

\begin{tabular}{|c|c|c|c|}
\hline Study factor & $\mathbf{n}$ & $\%$ & $p^{1}$ \\
\hline \multicolumn{4}{|l|}{ BMI } \\
\hline Underweight & 7 & 1.1 & \multirow{6}{*}{$<0.001$} \\
\hline Normal weight & 173 & 28.2 & \\
\hline Overweight & 276 & 45.0 & \\
\hline Obese type I & 127 & 20.7 & \\
\hline Obese type II & 24 & 3.9 & \\
\hline Obese type III & 7 & 1.1 & \\
\hline \multicolumn{4}{|l|}{ Arterial Pressure } \\
\hline Excellent & 172 & 28.2 & \multirow{6}{*}{$<0.001$} \\
\hline Normal & 195 & 31.9 & \\
\hline Borderline & 135 & 22.1 & \\
\hline Hypertension stage 1 & 85 & 13.9 & \\
\hline Hypertension stage 2 & 21 & 3.4 & \\
\hline Hypertension stage 3 & 3 & 0.5 & \\
\hline \multicolumn{4}{|l|}{ Glycemia } \\
\hline$\square 126$ & 89 & 14.8 & \multirow{2}{*}{$<0.001$} \\
\hline$<126$ & 511 & 85.2 & \\
\hline
\end{tabular}

TABLE 2 - Prevalence of comorbidities by socioeconomic factors

\begin{tabular}{|c|c|c|c|c|}
\hline \multirow[b]{2}{*}{ Study factor } & \multicolumn{4}{|c|}{ Comorbidity } \\
\hline & Obesity & $\begin{array}{l}\text { Metabolic } \\
\text { syndrome }\end{array}$ & $\begin{array}{c}\text { Arterial } \\
\text { hypertension }\end{array}$ & $\begin{array}{l}\text { Diabetes } \\
\text { mellitus }\end{array}$ \\
\hline \multicolumn{5}{|l|}{ Gender } \\
\hline Male & 27.1 & 6.3 & 24.3 & 7.0 \\
\hline Female & 24.4 & 2.3 & 11.4 & 2.7 \\
\hline $\mathrm{p}$ & 0.432 & 0.017 & $<0.001$ & 0.014 \\
\hline \multicolumn{5}{|l|}{ Age } \\
\hline 18-29 years & 13.3 & 1.7 & 5.0 & 1.8 \\
\hline 30-39 years & 34.4 & 1.1 & 11.7 & 1.1 \\
\hline $40-49$ years & 25.0 & 2.5 & 11.8 & 2.5 \\
\hline $50-59$ years & 29.6 & 5.0 & 19.1 & 6.5 \\
\hline $60-69$ years & 27.5 & 6.5 & 25.9 & 7.5 \\
\hline$>=70$ years & 12.7 & 8.2 & 32.8 & 8.2 \\
\hline$p$ & 0.008 & 0.144 & $<0.001$ & 0.093 \\
\hline \multicolumn{5}{|l|}{ Level of education } \\
\hline No schooling & 0.0 & 0.0 & 50.0 & 0.0 \\
\hline Primary comp/incomp & 43.1 & 14.6 & 29.4 & 14.9 \\
\hline $\begin{array}{l}\text { Secondary comp/ } \\
\text { incomp }\end{array}$ & 29.6 & 4.3 & 20.1 & 5.9 \\
\hline Higher comp/incomp & 22.6 & 2.9 & 15.4 & 3.2 \\
\hline$p$ & 0.005 & $<0.001$ & - & 0.001 \\
\hline \multicolumn{5}{|l|}{ Household income } \\
\hline $1 \mathrm{MW}$ & 35.6 & 7.0 & 22.0 & 9.3 \\
\hline$>1-3 \mathrm{MW}$ & 32.0 & 6.5 & 26.6 & 7.3 \\
\hline $4-10 \mathrm{MW}$ & 17.6 & 2.3 & 14.9 & 3.0 \\
\hline $10-20 \mathrm{MW}$ & 26.8 & 3.0 & 15.0 & 3.1 \\
\hline Over $20 \mathrm{MW}$ & 23.3 & 5.6 & 15.1 & 5.6 \\
\hline$p$ & 0.017 & 0.264 & 0.052 & 0.170 \\
\hline
\end{tabular}

\section{Prevalence of MS and its components}

Twenty-six individuals with MS were identified $(4.3 \%$ of the total), mostly male (6.3\%). MS was also found to be more prevalent in the obese than the non-obese $(9.8 \%$ vs. $2.4 \%$; $\mathrm{p}<0.001$, Table 3).

The prevalence of MS increased with age: $8.2 \%$ of patients ${ }^{3} 70$ years and $1.7 \%$ in the $18-29$ year age bracket (Table 2 ).
SAH, hyperglycemia and DM2 were also found to be present in $17.8 \%, 8.3 \%$ and $5.5 \%$ of cases, respectively (Tables 1 and 3). Abdominal obesity, characterized by increased abdominal circumference, was the most prevalent component of MS, being found in $70.1 \%$ of men and $73.8 \%$ of women (Table 4).

TABLE 3 - Distribution of metabolic syndrome by presence or absence of obesity and nutritional status vs glycemia

\begin{tabular}{|c|c|c|}
\hline \multirow{2}{*}{ BMI } & \multicolumn{2}{|c|}{ Metabolic syndrome } \\
\hline & Yes & No \\
\hline Not obese & 11 (2.4\%) & $441(97.6 \%)$ \\
\hline Obese & 15 (9.8\%) & $138(90.2 \%)$ \\
\hline Obese and not obese & $26(4.3 \%)$ & $579(95.7 \%)$ \\
\hline
\end{tabular}

$\mathrm{p}$ test of independence $<0.001$ : Odds ratio $=4.08(1.89-8.58)$

\begin{tabular}{ccccc|} 
Nutritional & \multicolumn{4}{c|}{ Glycemia } \\
\cline { 2 - 5 } Status & $<100$ & ${ }^{3} 100$ e $<126$ & ${ }^{3} 126$ e $<200$ & ${ }^{3} 200$ \\
\hline Fasting & $75(76.5 \%)$ & $15(15.3 \%)$ & $6(6.1 \%)$ & $2(2.0 \%)$ \\
\hline After eating & $258(53.1 \%)$ & $150(30.9 \%)$ & $57(11.7 \%)$ & $21(4.3 \%)$ \\
Random & $3(33.3 \%)$ & $4(44.4 \%)$ & $4(44.4 \%)$ & $0(0 \%)$ \\
\hline
\end{tabular}

Influence of demographic and anthropometric factors

While MS was found to be more prevalent in men $(6.3 \%$ vs $2.3 \% ; p=0.017)$, the occurrence of obesity did not differ between men and women $(27.1 \%$ vs $24.4 \% ; p=0.432)$ (Table 2). The components of MS found to be more frequent in men were DM2 (7.0\% vs $2.7 \% ; p=0.014)$ and SAH $(24.3 \%$ vs $11.4 \%$; $\mathrm{p}<0.001$ ), while the frequency of abdominal obesity was similar for men and women (70.1 vs 73.8\%; $p=0.309$ ) (Table 4).

TABLE 4 - Prevalence of increased abdominal circumference by gender and age bracket

\begin{tabular}{|l|c|}
\hline \multicolumn{1}{|c}{ Study factor } & Increased abdominal circumference \\
\hline Gender & 70.1 \\
\hline Male (\%) & 73.8 \\
\hline Female (\%) & 0.309 \\
\hline $\mathrm{p}^{1}$ & \\
\hline Age bracket & 31.7 \\
\hline $18-29$ years (\%) & 65.3 \\
\hline $30-39$ years (\%) & 71.4 \\
\hline $40-49$ years (\%) & 75.0 \\
\hline $50-59$ years (\%) & 88.0 \\
\hline $60-69$ years (\%) & 84.1 \\
\hline${ }^{3} 70$ years (\%) & $<0.001$ \\
\hline $\mathrm{p}^{1}$ & \\
\hline
\end{tabular}

So far as age bracket is concerned, obesity was more prevalent among those aged $30-39$ years (34.4\%), while the prevalence of MS increased with age, being low among those aged $18-29$ years $(1,7 \%)$ and higher in individuals aged over $70(8.2 \%)(p=0.144)$. The prevalence of the components of MS (SAH, DM2 and increased abdominal circumference) also increased with age (Tables 2 and 4 ).

\section{Influence of socioeconomic factors}

The participants who had only primary school education were those who had the highest prevalence of the comorbidities under study (43.1\% for obesity and $14.6 \%$ for MS). As for the influence of household income, the participant with up to one minimum wage were those who had the highest prevalence of obesity (35.6\%) and MS (7\%, Table 2). 
Influence of physical exercise

With regard to physical exercise, the sedentary participants had a higher prevalence of obesity and metabolic syndrome (though not statistically significant) (Table 5).

TABLE 5 - Prevalence of obesity and metabolic syndrome by physical activity

\begin{tabular}{|c|c|c|}
\hline Variable & Obesity & $\begin{array}{c}\text { Metabolic } \\
\text { syndrome }\end{array}$ \\
\hline Physical exercise & & \\
\hline Yes & 23.9 & 3.8 \\
\hline No & 32.6 & 6.0 \\
\hline $\mathrm{p}^{1}$ & 0.042 & 0.271 \\
\hline Frequency of physical activity (weekly) & & \\
\hline None & 32.6 & 6.0 \\
\hline 1-2 times & 32.5 & 3.8 \\
\hline 3 times & 20.2 & 2.5 \\
\hline $4-5$ times & 22.7 & 4.6 \\
\hline $6-7$ times & 22.9 & 4.3 \\
\hline$p$-value & \\
\hline${ }^{1}$ Chi-squared test & 0.078 & 0.751 \\
\hline
\end{tabular}

\section{Influence of obesity and abdominal circumference}

Glycemia levels $126 \mathrm{mg} / \mathrm{dl}$ were found to be significantly more prevalent in the obese individuals than in those that were not obese $(24.3 \%$ vs $11.7 \%$; $p<0.001)$, with an odds ratio of 2.44 (IC=1.48-4.00) (Table 6), and in those with increased abdominal circumference $(p<0.001$, Table 6$)$. The relation between metabolic syndrome and obesity was also found to be significant $(p<0.001)$, with an odds ratio of $4.08(\mathrm{CI}=1.89-8.58$, Table 3$)$.

TABLE 6 - Distribution of glycemia according to the presence or absence of obesity and abdominal circumference

\begin{tabular}{|c|c|c|}
\hline \multirow{2}{*}{ BMI } & \multicolumn{2}{|c|}{ Glycemia* } \\
\cline { 2 - 3 } & ${ }^{3} 126 \mathrm{mg} / \mathrm{dL}$ & $<126 \mathrm{mg} / \mathrm{dl}$ \\
\hline Not obese & $52(11.7 \%)$ & $394(88.3 \%)$ \\
\hline Obese & $37(24.3 \%)$ & $115(75.7 \%)$ \\
\hline All & $89(14.9 \%)$ & $509(85.1 \%)$ \\
\hline
\end{tabular}

*Patients fasting and after eating; $p$ for test of independence $<0.001$; Odds ratio $=2.44(\mathrm{CI}=1.48-4.00)$

\begin{tabular}{c|c|c|}
\multirow{2}{*}{ AC } & \multicolumn{2}{|c|}{ Glycemia } \\
\cline { 2 - 3 } & ${ }^{3} 126 \mathrm{mg} / \mathrm{dL}$ & $<126 \mathrm{mg} / \mathrm{dL}$ \\
\hline Normal & $14(6.9 \%)$ & $190(93.1 \%)$ \\
\hline Increased & $73(18.8 \%)$ & $315(81.2 \%)$ \\
\hline All & $87(14.7 \%)$ & $505(85.3 \%)$ \\
\hline
\end{tabular}

$\mathrm{AC}=$ abdominal circumference; $\mathrm{p}$ for test of independence $<0.001 ;$ Odds ratio $=3.15$ $\mathrm{CI}=1.67-6.01)$

\section{DISCUSSION}

The present study forms part of a broader project that aims to trace the epidemiological profile and prevalence of obesity and comorbidities among users of a park - chosen on account of the large numbers who visit it - both to engage in physical activities and walk.

Of the participants, $72 \%$ presented with abdominal obesity, $45 \%$ overweight, $25.7 \%$ obesity, $17.8 \%$ SAH, $8.3 \%$ hyperglycemia, $5.5 \%$ DM2 and $4.3 \% \mathrm{MS}$. All these conditions were found to be significantly more prevalent in men, with the exception of obesity and abdominal obesity, whose prevalence was similar in both genders. MS and its components were significantly more frequent in obese individuals than in the non-obese and its prevalence increased notably with age.
Obesity is a major public health problem, with growing numbers of people affected and serious comorbidities and mortality associated with the condition $n^{9,13,17}$. A recent study examining the prevalence of obesity and overweight around the world found that, in Brazilian men and women aged over 20 years, the rates for overweight and obesity were $52.5 \%$ and $58.4 \%$, respectively, while the corresponding prevalence for obesity alone was $11.7 \%$ and $20.6 \%{ }^{17}$. Similar results have been reported by Ministry of Health studies, in which around half (50.8\%) of the Brazilian population was found to be overweight, the proportion of individuals with BMI $25 \mathrm{~kg} / \mathrm{m}^{2}$ increased from $42.7 \%$ in 2006 to $50.8 \%$ in 2013 (54.7\% in men and $47.4 \%$ in women $)^{16}$. There was also found to be a prevalence of obesity (BMI $30 \mathrm{~kg} / \mathrm{m}^{2}$ ) of $17.5 \%$ (16.4\% in men and $19.2 \%$ in women $)^{16}$. This survey was conducted by VIGITEL (Telephone Surveillance of Risk and Protective Factors for Chronic Diseases) and the data were collected in 26 Brazilian state capitals and the Federal District ${ }^{16}$. Compared with the current state of affairs, these results call attention to the higher prevalence of obesity (25.7\%) in both men (24.4\%) and women (27\%). This difference may be due to many people visiting the park to lose weight by engaging in physical activity.

Data on the prevalence of MS are still limited in the country. A recent systematic review, involving nine cross-sectional studies, showed that its prevalence in Brazil varied from $14.9 \%$ to $65.3 \%$, with the highest percentage found in the indigenous population of Rio Grande do Sul ${ }^{23}$. The mean prevalence was $29.8 \%$ in urban areas, $20.1 \%$ in rural areas and $41.5 \%$ among indigenous peoples, with an overall mean prevalence of $28.9 \%$ and $29.5 \%$, according to criteria used to define $\mathrm{MS}^{23}$.

The lower prevalence of MS found in the present study, compared with the Brazilian systematic review and that reported in some other countries $3,4,5,7,15,19,24,2526$ may be explained by the characteristics of the sample $(1.7 \%$ aged $<30$ years) or, more likely, by the fact that levels of triglycerides and $\mathrm{HDL}$-cholesterol were not included in the diagnosis of MS. Moreover, the fact that only $20 \%$ of the participants were fasting hindered the evaluation of glycemic status and certainly led to underestimation of the prevalence of hyperglycemia. It has been widely demonstrated that the occurrence of MS increases with age and is much less frequent in those aged under 30 years ${ }^{5,11,23}$ and this is in keeping with the findings of the present study. Only $17 \%$ of university students in Fortaleza, CE, Brazil were found to have MS, but the syndrome affected $33 \%$ of overweight individuals and $41.7 \%$ of those who were obese ${ }^{6}$. Of 321 overweight adolescents (10-16 years) in Botucatu, SP, Brazil, around $18 \%$ were found to have $\mathrm{MS}^{20}$. In the present study, only $1.7 \%$ of participants aged under 30 years presented with MS.

DM2 is a serious condition associated with increased morbimortality and an estimated 4.9 million deaths in 20142,10,21,26. In the same year, the IDF estimated that DM2 affected 387 million individuals around the world (a prevalence of 8.3\%), with a projected 205 million new cases by $2035^{10}$. According to data from the latest VIGITEL study, the mean prevalence of diabetes reported in adults was $6.9 \%$ (6.5\% in men and $7.2 \%$ in women) but increased with age, reaching $22.1 \%$ in the group 65 years $^{16}$. Around $8 \%$ of those interviewed in Recife reported having received a medical diagnosis of $\mathrm{DM} 2^{16}$. Overall, the prevalence of DM2 was higher (14.9\%) in individuals with up to eight years of schooling. Of those interviewed, only $5.5 \%$ had DM2, but the disease affected $8.2 \%$ of individuals aged over 70 years. The fact that most of the participants had eaten, as noted above, certainly led to an underestimation of the occurrence of DM2.

A high prevalence of diabetes was also found by a study conducted in 2008/2009 in Triunfo, a small city in the Sertão Region of Pernambuco. In fact, 27 (13.6\%) of 198 were diagnosed as having DM2 (8.8\% of men and 16.2 of women $)^{14}$. In that study, $80 \%$ of participants had only primary school education and $81.3 \%$ a household income of less than one minimum wage ${ }^{14}$. 
In the present study, DM2 was also more prevalent among individuals with only primary school education (14.9\%), but there was no significant difference with regard to monthly income.

MS was also found to be more prevalent in the group aged over 70 years, increasing the risk of cardiovascular diseases for this age group, while obesity was more prevalent in those aged between 30 and 39 years. These findings show that increasingly younger people are being affected and at greater risk of developing MS. Participants with lower levels of education were those with the highest prevalence of comorbidities, especially $\mathrm{SAH}$. Obesity was found to be more prevalent in participants with an income of up to one minimum wage, showing that the least privileged social strata are more prone to the disease, which may be due to greater consumption of cheaper, less healthy, high-calorie food products.

Some limitations of the present study should be pointed out. The study setting did not allow for more complex tests (such as lipid levels) to be carried out and most participants were not fasting. Neither was it possible to conduct follow-up observations.

Interventions such as the one carried out here should be encouraged and adopted by public institutions in other leisure areas in the country, resulting in greater education of a population that is often unaware of its true state of health and aiming primarily to prevent such problems.

\section{CONCLUSION}

The findings show a high prevalence of overweight and obesity in the studied population and metabolic syndrome in $4.3 \%$, despite $70 \%$ of participants reporting regular physical activity.

\section{REFERENCES}

1. AlbertiKGMM, EckelRH, Grundy SM, etal. Harmonizing the metabolic syndrome: a joint interim statement of the international diabetes federation task force on epidemiology and prevention; national heart lung, and blood institute; american heart association; world heart federation; international atherosclerosis society; and international association for the study of obesity. Circulation 2009;120(16):1640-5

2. American Diabetes Association. Diagnosis and classification of diabetes mellitus. Diabetes Care 2012; 35 (suppl 1):S64-71.

3. Azimi-Nezhad M, Herbeth B, Siest G, et al. High prevalence of metabolic syndrome in Iran in comparison with France: what are the components that explain this? Metab Syndr Relat Disord 2012;10(3):181-8.

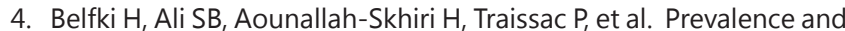
determinants of the metabolic syndrome among Tunisian adults: results of the transition and health impact in North Africa (TAHINA) project. Public Health Nutr 2012;16(04):582-90.

5. Beltrán-Sánchez H, Harhay MO, Harhay MM, McElligottS. Prevalence and trends of metabolic syndrome in the adult US population, 1999-2010. J Am Coll Cardiol 2013;62(8):697-703.

6. de Freitas RW Jr, de Araújo MF, Marinho NB, et al. Prevalence of the metabolic syndrome and its individual components in Brazilian college students. J Clin Nurs 2013;22(9-10):1291-8.

7. Fonseca MJ, Gaio R, Lopes C, Santos AC: Association between dietary patterns and metabolic syndrome in a sample of Portuguese adults. Nutr J 2012;11:64.
8. Gami AS, Witt BJ, Howard DE, et al. Metabolic syndrome and risk of incident cardiovascular events and death: a systematic review and meta-analysis of longitudinal studies.J Am Coll Cardiol 2007;49(4):40314.

9. Haslam DW, James WP. Obesity. Lancet 2005;366:1197-209.

10. International Diabetes Federation. Diabetes Atlas, sixthedition. Disponível em:http://www.idf.org/sites/default/files/Atlas-poster-2014_EN.pdf.

11. International Diabetes Federation. The IDF consensus worldwide definition of the metabolic syndrome. http://www.idf.org/webdata/ docs/IDF_Meta_def_final.pdf

12. Isomaa $\mathrm{B}$, Almgren $\mathrm{P}$, Tuomi $\mathrm{T}$, et al. Cardiovascular morbidity and mortality associated with the metabolic syndrome. Diabetes Care 2001:24(4):683-9.

13. Li Z, Bowerman S, Heber D. Health ramifications of the obesity epidemic. Surg Clin North Am 2005;85(4):681-701.

14. Lyra R, Silva R dos S, Montenegro RM Jr, Matos MV, Cézar NJ, Maurício-da-Silva $L$ Prevalence of diabetes and associated factors in an urban adult population of low educational level and income from the Brazilian Northeast wilderness. Arq Brasil Endocrinol Metab 2010;54(6):560-6

15. Medina-Lezama J, Zea-Diaz H, Morey-Vargas OL, et al. Prevalence of the metabolic syndrome in Peruvian Andean hispanics: the PREVENCION study. Diabetes Res Clin Pract 2007;78(2):270-81.

16. Ministério da Saúde. VIGITEL Brasil 2013. Disponível em: https:// biavati.files.wordpress.com/2014/05/vigitel-2013.pdf

17. Ng M, Fleming $T$, Robinson $\mathrm{M}$, et al. Global, regional, and national prevalence of overweight and obesity in children and adults during 1980 - 2013: a systematic analysis for the Global Burden of Disease Study 2013. Lancet 2014;384(9945):766-8.

18. Pinheiro ARO, Freitas SFT, Corso ACT. Uma abordagemepidemiológica da obesidade. Rev Nutr 2004;17(4):523-33.

19. Pinzón JB, Serrano NC, DíazLA, etal.Impacto de las nuevas definiciones en la prevalencia del síndrome metabólico en una población adulta de Bucaramanga, Colombia. Biomedica 2007;27(2):172-9.

20. Rizzo ACB, Goldberg TBL, Silva CC, Kurokawa CS, Nunes HRC, Corrente JE. Metabolic syndrome risk factors in overweight, obese, and extremely obese brazilian adolescents. Nutri J 2013;12:19.

21. Sociedade Brasileira de Cardiologia. Sociedade Brasileira de Endocrinologia e Metabologia. Sociedade Brasileira de Diabetes. I Diretriz brasileira de diagnóstico e tratamento da síndrome metabólica. Arq Bras Cardiol 2005; 84 (supl 1):3-28.

22. VI Diretrizes Brasileiras de Hipertensão-DBH VI. Rev Bras Hipertens 2010;17(1):11-7.

23. Vidigal FC, Bressan J, Babio N, Salas-Salvadó J. Prevalence of metabolic syndrome in Brazilian adults: a systematic review. BMC Public Health 2013:13:1198.

24. Wagner A, Dallongeville J, Haas B, et al. Sedentary behaviour, physical activity and dietary patterns are independently associated with the metabolic syndrome. Diabetes Metab 2012;38(5):428-35.

25. Wang GR, Li L, Pan YH, et al. Prevalence of metabolic syndrome among urban community residents in China. BMC Public Health 2013;13(1):599

26. Wild S, Roglic G, Green A, Sicree R, King H. Global prevalence of diabetes: estimates for the year 2000 and projections for 2030 . Diabetes Care 2004:27(5):1047-53.

27. World Health Organization. Obesity: preventing and managing the global epidemic. Report of a World Health Organization Consultation. Geneva: World Health Organization, 2000. p. 256. WHO Obesity Technical Report Series, n. 284. 